\title{
Geriatric patients' expectations of their physicians: findings from a tertiary care hospital in Pakistan Taimur Saleem*1, Umair Khalid ${ }^{1}$ and Waris Qidwai ${ }^{2}$
}

\author{
Address: ${ }^{1}$ Medical College, The Aga Khan University, Stadium Road, Karachi 74800, Pakistan and ${ }^{2}$ Department of Family Medicine, The Aga Khan \\ University, Stadium Road, Karachi 74800, Pakistan \\ Email: Taimur Saleem* - taimur@gmail.com; Umair Khalid - uk2017@gmail.com; Waris Qidwai - waris.qidwai@aku.edu \\ * Corresponding author
}

Published: 13 November 2009

BMC Health Services Research 2009, 9:205 doi:10.1 186/1472-6963-9-205

Received: 18 May 2009

Accepted: 13 November 2009

This article is available from: http://www.biomedcentral.com//472-6963/9/205

(C) 2009 Saleem et al; licensee BioMed Central Ltd.

This is an Open Access article distributed under the terms of the Creative Commons Attribution License (http://creativecommons.org/licenses/by/2.0), which permits unrestricted use, distribution, and reproduction in any medium, provided the original work is properly cited.

\begin{abstract}
Background: Geriatric health is a neglected and under-explored area internationally and in Pakistan. We aimed to ascertain the expectations of the geriatric patients from their physicians and the factors associated with patient satisfaction in this particular age bracket.

Methods: A cross-sectional survey was carried out at a tertiary care teaching hospital in Karachi, Pakistan. Data collection was carried out via face-to-face interviews based on structured, pretested questionnaires. All consenting individuals aged 65 years or above were recruited into the study. Convenience sampling was used to draw the sample. The data was analyzed using SPSS version 16. Geriatric patient's expectations from physicians were elicited using a set of II questions that were graded on a scale of I-3 where I = not important, 2 = important, 3 = very important.

Results: Three hundred and eighty geriatric patients were interviewed. The response rate of this study was $89.8 \%$. The mean age of the respondents was $73.4 \pm 6.8$ years. Two hundred and forty eight respondents (65.3\%) were female. Diabetes mellitus (53.7\%), hypertension (59.5\%), arthritis (40.5\%) and renal disease (32. $1 \%$ ) were common ailments among geriatric patients. More than $50 \%$ of the patients were visiting their physicians once every two to three months. Discussing treatment options and letting patients make the final decision (79.2\%), prescribing minimum possible medications (84.5\%), physician's holistic knowledge about the spectrum of care issues for geriatric patients $(79.2 \%)$, being given a realistic but optimistic picture of future health by physicians ( $85.5 \%)$ were ranked as very important expectations by patients from their physicians. Cumulative household income $(p=0.005)$, most important health complaint $(p=0.0 \mathrm{I})$ and frequency of experiencing health complaint $(\mathrm{p}<0.00 \mathrm{I})$ emerged as independent predictors of the satisfaction of geriatric patients from care provided by physicians.
\end{abstract}

Conclusion: We have documented the expectations of the geriatric patients from their physicians in a developing country. Physicians belonging to all disciplines should keep these expectations in mind during clinical encounters with geriatric patients.

\section{Background}

Geriatric population is a rapidly growing age bracket globally. The majority of this elderly population $(60 \%$ of the
580 million elderly people globally) is living in the developing countries. By 2020, this value will increase to $70 \%$ of the total elderly population [1]. It is estimated that 
between 2000 and 2050, the proportion of individuals above the age of 65 will more than double from $6.9 \%$ to $16.4 \%$ [2]. Pakistan, currently the sixth most populous country in the world, has an estimated geriatric population of around 7 million [3]. However, this segment of the society is not receiving its due share of health services despite facing a myriad of medical problems $[4,5]$. Issues such as paucity of appropriate retirement benefits and pensions [6] as well as the evanescence of the traditional joint family system in Pakistan are important considerations for the geriatric population [7].

The universe of the health care delivery system centers on patients. It is, therefore, important to procure their input regarding health services and their expectations from such services. This may improve the level of patient satisfaction [8] and also favorably impact the effectiveness of the consultation [9].

A thorough MEDLINE search revealed that although literature regarding the expectations of geriatric patients from healthcare services is available, this literature is geared towards very specific aspects of geriatric healthcare; for example expectations towards implantable cardioverterdefibrillators [10], day-care rehabilitation services [11], social services [12], various surgical services such as vascular, cardiac and spinal surgery [13-15], percutaneous transluminal coronary angioplasty [16] and nursing homes [17]. At other times, the available literature has focused on specific groups of geriatric patients; for example stroke patients [18], hypertensive patients [19], dialysis patients [20], patients recovering from surgery [21] or institutionalized patients [22]. Still further, research has focused on healthcare professionals other than physicians such as nurses [23]. Our literature search revealed a dearth of information with regards to the general expectations of geriatric patients from physicians generally and especially in Pakistan despite a sizeable population being 65 years and above. Therefore, both medical and mental health of geriatric patients runs the risk of under-treatment and under-recognition.

According to World Health Organization (WHO), "health is a state of complete physical, mental and social wellbeing and not merely the absence of disease or infirmity" [24]. Caring for the elderly not only comprises medical and technical aspects but the psychological and social dimensions of health as well [25]. Therefore, physicians should be cognizant of the complete spectrum of health needs of geriatric patients. We carried out a survey among a selected geriatric patient population in Karachi, the largest metropolitan of Pakistan, to ascertain their general expectations from physicians. We also aimed to determine the factors associated with patient satisfaction among this particular age demographic. Physicians can assimilate this knowledge into their practice to make the care provided more meaningful and effective [26].

\section{Methods}

\section{Study design and site}

We conducted a cross-sectional survey to gauge the expectations of the geriatric patients at the Community Health Centre (CHC) at The Aga Khan University Hospital (AKUH), Karachi, Pakistan. AKUH is a tertiary level teaching facility in the private sector and caters to the medical needs of a large majority of patients coming from all over Karachi as well as from other parts of Pakistan. Consenting geriatric patients encountered in the waiting area of the CHC clinics were recruited into the survey over a one month period. CHC clinics were chosen because they are attended by a large number of people from all walks of life and all ages. These clinics cater to patients from almost all socioeconomic classes. Another important consideration in selection of CHC was that it not only runs family medicine clinics, but also provides specialist services to a number of patients. Therefore, a diverse assortment of patients from all backgrounds was expected to be encountered there.

\section{Study sample and data collection}

We required a sample size of 385 to fulfill our objectives at $95 \%$ confidence interval, and 5\% sample error. This sample size was calculated assuming a $50 \%$ variance due to paucity of prior studies on the subject. It was further adjusted for a $10 \%$ non-response rate; bringing the total sample size to 420 respondents. Convenience sampling was used to draw the sample. All consenting individuals aged 65 years and above and visiting the $\mathrm{CHC}$ between 10 am to $4 \mathrm{pm}$ were interviewed. Information was collected using face-to-face interviews based on a structured, pretested questionnaire. We anticipated the potential problem that elderly patients may experience in filling the questionnaires; therefore they were interviewed rather than being asked to fill in questionnaires by hand. People who could not comprehend the questions asked by the interviewers, either due to a language barrier or severe cognitive impairment were excluded from the survey. The questionnaire was thoroughly discussed among the interviewers before data collection to decrease interview bias.

\section{Questionnaire [see Additional File I] a. Development}

The initial questionnaire was developed on the basis of literature search and prior experience of investigators. In addition, colleagues, peers, patients and their attendants were explained about the study and its objectives in simple and clear language and their informal input was sought. Their suggestions were incorporated into the questionnaire. The questionnaire so prepared was then formally pre-tested on 25 respondents of the target popu- 
lation. The pre-testing enabled investigators to ascertain the conceptual deficiencies as well as the feasibility of the administration of the data collection tool. Ambiguities and duplications in the questionnaire were removed and clarity was introduced. Our final questionnaire was a result of these efforts. The results of the pre-testing were not included in the final analysis of the data.

\section{b. Efforts to reduce bias}

A meeting of the investigators was held prior to data collection in order to maintain uniformity in the manner the face-to-face interviews were conducted; hence reducing chances of interviewer's bias in the study.

\section{c. Linguistic validation of questionnaire}

The questionnaire was initially prepared in English; then translated into Urdu, the national language of Pakistan, for the convenience of the respondents. The questionnaire was also back-translated into English by two non-medical personnel to check for any paraphrasing errors. This provided linguistic validation for the questionnaire.

\section{d. Contents of questionnaire}

The questionnaire consisted of four sections.

I - Section one dealt with the socio-demographic details of the respondents.

II - Section two briefly enquired about the medical ailments and symptomatology of participants.

III - Section three contained a set of questions aimed at eliciting the geriatric patient's expectations from his physician using a scale of 1-3 where $1=$ not important, $2=$ important, 3 = very important.

IV - Section four enquired about the frequency of visits of geriatric patients to the doctor along with overall satisfaction with treatment provided.

\section{Data management and statistical analysis}

Data was entered twice and validated using Windows Statistical Package for Social Sciences (SPSS) version 16.0. It was cleaned for invalid and out of range values, missing values and duplicate ID numbers. The data was then analyzed using the same software. As part of descriptive statistics, mean, median, mode and standard deviations were used to express the continuous data while proportions were calculated for categorical data. Associations were assessed using Chi-square test and Fisher's exact test where appropriate. For all analysis performed for the data set, the level of significance $(\alpha)$ was set as 0.05 . Variables with a significant p-value in chi-square testing were further subjected to a multiple logistic regression analysis to determine factors which are independent predictors of the satisfaction of geriatric patients from the care provided. All odds ratios were recorded with a $95 \%$ confidence interval. As s further step, we also determined the goodness of fit of the model to measure how well it described our response variable by using Hosmer-Lemeshow test.

\section{Ethical Considerations}

Informed consent for participation in the survey was obtained from the respondents of the survey; this consent was either written or verbal. Strict confidentiality of the information was maintained throughout the process of data collection, entry and analysis. All efforts were made in this study to fulfill the ethical considerations in accordance with the 'Ethical principles for medical research involving human subjects' of Helsinki Declaration [27]. The confidentiality of each participant was strictly ensured throughout the project. The study was approved by the Ethical Review Committee (ERC) at the Department of Community Health Sciences, Aga Khan University Hospital.

\section{Results}

A total of 423 geriatric patients were approached for this survey. Forty three patients declined to participate while 380 patients completed the full interviews. Therefore, the response rate of this study was $89.8 \%$.

\section{Socio-demographic characteristics}

The mean age of the respondents was $73.4 \pm 6.8$ years. Two hundred and forty eight respondents $(65.3 \%)$ were female. Diabetes mellitus (53.7\%), hypertension (59.5\%), arthritis (40.5\%), renal disease $(32.1 \%)$ and ischemic heart disease $(25.3 \%)$ were common ailments afflicting the geriatric population in our sample. However, cancer $(5 \%)$ and cerebrovascular accident $(11.1 \%)$ were less common. When enquired about their most important health complaints, geriatric patients reported urinary incontinence $(22.4 \%)$, myalgias or arthralgias $(20.3 \%)$, and memory loss $(13.9 \%)$ as important health complaints. With regards to the frequency of visits to the doctor, more than $50 \%$ of the patients were visiting their physicians at least once every two to three months. A total of 83 participants were current smokers. Out of these 83 individuals, $48(57.8 \%)$ were males and $35(42.2 \%)$ were females. The association between current smoking status and gender was statistically significant $(\mathrm{p}<0.001)$. The baseline characteristics of our sample are shown in table 1.

\section{Geriatric patients' expectations from their physicians}

Table 2 shows the response of the geriatric patients when asked about their expectations from their physicians in terms of various aspects of care. This was done by providing statements and asking the geriatric patients to rank them on a scale of 1 to 3 with 1 being not important and 
Table I: Baseline characteristics of geriatric patients in our sample

\begin{tabular}{|c|c|c|}
\hline Baseline Characteristics & $\begin{array}{r}\text { Frequency } \\
(n=380)\end{array}$ & $\%$ \\
\hline \multicolumn{3}{|l|}{ Age in years } \\
\hline$-65-70$ & 160 & 42.1 \\
\hline$-7 \mid-75$ & 71 & 18.7 \\
\hline$-76-80$ & 76 & 20 \\
\hline$-8 \mid-85$ & 58 & 15.3 \\
\hline$-85-90$ & 15 & 3.9 \\
\hline \multicolumn{3}{|l|}{ Gender } \\
\hline -Male & 132 & 34.7 \\
\hline -Female & 248 & 65.3 \\
\hline \multicolumn{3}{|l|}{ Marital Status } \\
\hline -Single & 52 & 13.7 \\
\hline -Married (and living with spouse) & 179 & 47.1 \\
\hline -Divorced or Separated & 57 & 15 \\
\hline -Widowed & 92 & 24.2 \\
\hline \multicolumn{3}{|l|}{ Education } \\
\hline -Illiterate/Can read or write name only & 56 & 14.7 \\
\hline -Up to Primary* & 58 & 15.3 \\
\hline -Up to Secondary $* *$ & 70 & 18.4 \\
\hline -Up to Higher Secondary $* * *$ & 108 & 28.4 \\
\hline -Graduation or Post graduation & 88 & 23.2 \\
\hline
\end{tabular}

\section{Cumulative household income in Pakistani Rupees ^}

$-<5000$

$-5000-10,000$

$->10,000-25,000$

$->25,000-50,000$

$->50,000-100,000$

$->100,000$

Frequency of experiencing health complaints

- Daily

- 2-5 times a week

- Once a week

- Twice or thrice a month

- Once a month

- Less frequently than once a month

\section{Frequency of Visits to the Doctor}

- Weekly

- Every 2-4 weeks

- Every 2-3 months

- Every 6 months

- Annually

$\begin{array}{rr}18 & 4.7 \\ 40 & 10.5 \\ 239 & 62.9 \\ 70 & 18.4 \\ 13 & 3.4\end{array}$

\section{Currently Smoking}

Yes

No

\footnotetext{
* Upto grade 5, ** Upto grade 10, *** Upto grade 12, ^ I US \$: 83.23 PK Rupees
} 
Table 2: Geriatric patients' expectations from their physicians

\begin{tabular}{|c|c|c|c|}
\hline \multirow[t]{2}{*}{ Expectations from physicians in terms of } & \multicolumn{3}{|c|}{$n=380(\%)$} \\
\hline & Not Important & Important & Very Important \\
\hline I. Explaining the nature of the disease in clear and simple language & $59(15.5)$ & $93(24.5)$ & $228(60)$ \\
\hline 2. Letting you talk freely about your illness and problems & $48(12.6)$ & $\begin{array}{l}196(51.6) \\
(35.8)\end{array}$ & 136 \\
\hline 3. Involving your family and friends in the consultation with your permission & $161(42.4)$ & $\begin{array}{l}119(31.3) \\
(26.3)\end{array}$ & 100 \\
\hline 4. Discussing all available treatment options and letting you make the final decision & $28(7.4)$ & $\begin{array}{l}51(13.4) \\
(79.2)\end{array}$ & 301 \\
\hline 5. Prescribing minimum possible Medicines & $21(5.5)$ & $\begin{array}{l}38(10) \\
(84.5)\end{array}$ & 321 \\
\hline 6. Informing you about any side effects of treatment prescribed & $37(9.7)$ & $\begin{array}{l}202(53.2) \\
(37.1)\end{array}$ & $14 \mid$ \\
\hline 7. Telling you how long the illness will last and the number of follow-ups needed & $35(9.2)$ & $\begin{array}{l}63(16.6) \\
(74.2)\end{array}$ & 282 \\
\hline 8. Not refusing to treat you on the grounds of age & $106(27.9)$ & $\begin{array}{l}77(20.3) \\
(51.8)\end{array}$ & 197 \\
\hline 9. Knowing about the complete spectrum of care issues for elderly patients & $31(8.2)$ & $\begin{array}{l}48(12.6) \\
(79.2)\end{array}$ & 301 \\
\hline 10. Giving you a realistic but optimistic picture of your health and future & $22(5.8)$ & $\begin{array}{l}32(8.4) \\
(85.8)\end{array}$ & 326 \\
\hline II. Using both non-verbal and verbal gestures to comfort you when needed & $18(4.7)$ & $133(35)$ & $229(60.3)$ \\
\hline
\end{tabular}

3 being very important. For the geriatrics patients, aspects such as explaining the nature of the disease in clear and simple language $(60 \%)$, discussing all available treatment options and letting patients make the final decision $(79.2 \%)$, prescribing minimum possible medications (84.5\%), telling patients how long the illness will last and how many follow-ups are required $(74.2 \%)$, physician's holistic knowledge about the spectrum of care issues for geriatric patients $(79.2 \%)$, being given a realistic but optimistic picture of future health by their physicians (85.5\%) and use of both verbal and non-verbal gestures by their doctors to comfort them $(60.3 \%)$ were ranked as very important expectations.

\section{Satisfaction with care provided}

Two hundred and forty five patients (64.5\%) patients were fully satisfied that the care being provided to them by physicians was appropriate for their age demographic. However, 135 patients (35.5\%) were not fully satisfied with the care provided. We computed the association between various factors and the satisfaction of the geriatric patients from physicians as shown in table 3 . The satisfaction with the care provided by physician was significantly association with the age of the geriatric patients $(\mathrm{p}=0.009)$, most important health complaint ( $\mathrm{p}$ $=0.006)$, cumulative household income $(p=0.005)$, frequency of experiencing symptoms $(p<0.001)$ and frequency of visits to physician $(\mathrm{p}=0.01)$.

These variables were then further subjected to multiple logistic regression analysis to ascertain the independent predictors of the satisfaction of geriatric patients from physicians while adjusting for confounders (table 4). Factors such as cumulative household income $(\mathrm{p}=0.005)$, most important health complaint $(\mathrm{p}=0.01)$ and frequency of experiencing health complaints $(\mathrm{p}<0.001)$ emerged as independent predictors of the satisfaction of geriatric patients with the care provided. Frequency of visits to the doctor $(\mathrm{p}=0.06)$ and age of geriatric patients $(\mathrm{p}$ $=0.073$ ) were found to be marginally associated with the satisfaction of geriatric patients from the care provided.

The Hosmer-Lemeshow test of goodness of fit was not significant $\left(\chi^{2}=6.26, \mathrm{df}=8\right.$; significance $\left.=0.596\right)$; thus the model fits the data. The Nagelkerke $\mathrm{R}^{2}$, an adjusted version of the Cox \& Snell $\mathrm{R}^{2}$, was 0.183 ; providing a measure of effect size. The total percentage of the correct classification of the model was $65.3 \%$. Furthermore, the discrimination of the model was assessed using the area under the receiver operating characteristic curve (AUROC). The cstatistic, adjudged by AUROC, was $0.73 \pm 0.026[95 \%$ confidence interval: $0.68-0.78$ ).

\section{Discussion}

The age at which individuals are considered "elderly" or "geriatric" varies from study to study. However, by convention, age 65 is usually taken as the minimum age, which we also followed [28]. In our study, most of the participants were below the age of 70 owing to a relatively lower life expectancy in our region. We can explain this on the basis of the limited access of the elderly population to the healthcare services; probably poor risk factor control of chronic diseases and difference in genetic makeup of the population in developing countries as compared to 
Table 3: Association of various factors with the satisfaction of geriatric patients from care provided by their physicians

\begin{tabular}{|c|c|c|}
\hline \multirow[t]{2}{*}{ Variables } & \multicolumn{2}{|c|}{$\begin{array}{l}\text { Satisfaction with the level of care provided } \\
\qquad(n=380)\end{array}$} \\
\hline & Yes & No \\
\hline \multicolumn{3}{|l|}{ Age in years $(p=0.009)$} \\
\hline$-65-70$ & 106 & 54 \\
\hline$-7 I-75$ & 46 & 25 \\
\hline$-76-80$ & 41 & 35 \\
\hline$-81-85$ & 46 & 12 \\
\hline$-86-90$ & 6 & 9 \\
\hline \multicolumn{3}{|l|}{ Gender $(p=0.21)$} \\
\hline - Male & 81 & 51 \\
\hline - Female & 164 & 84 \\
\hline \multicolumn{3}{|l|}{ Marital status $(p=0.72)$} \\
\hline - Single & 35 & 17 \\
\hline - Married (and living with spouse) & 110 & 69 \\
\hline - Divorced/separated & 38 & 19 \\
\hline - Widowed & 62 & 30 \\
\hline \multicolumn{3}{|l|}{ Education $(p=0.22)$} \\
\hline - Illiterate or can read and write name only & 31 & 25 \\
\hline - Up to primary* & 40 & 18 \\
\hline - Up to secondary $* *$ & 43 & 27 \\
\hline - Up to higher secondary $* * *$ & 67 & 41 \\
\hline - Graduate or post graduate studies & 64 & 24 \\
\hline
\end{tabular}

Cumulative household income in $\mathrm{Pk}$ rupees ${ }^{\wedge}(p=0.005)$

$$
-<5,000
$$

$-5,000-10,000$

$->10,000-25,000$

$->25,000-50,000$

- > 50,000-100,000

- > 100,000

$\begin{array}{cc}35 & 16 \\ 44 & 12 \\ 70 & 28 \\ 70 & 51 \\ 16 & 20 \\ 10 & 8\end{array}$

Most important health complaint $(p=0.006)$

- Myalgias/arthralgias

- Dyspnea

- Nausea/vomiting

- Insomnia

-Anorexia

- Bed sores

- Urinary incontinence

- Urinary retention

- Fecal incontinence

- Constipation

- Memory loss

$\begin{array}{cc}40 & 37 \\ 4 & 6 \\ 8 & 3 \\ 15 & 13 \\ 13 & 9 \\ 9 & 4 \\ 60 & 25 \\ 12 & 5 \\ 25 & 3 \\ 29 & 7 \\ 30 & 23\end{array}$

Frequency of experiencing health complaints $(p<0.001)$

- Daily

- 2-5 times a week

- Once a week

- 2-3 times a month

- Once a month

- Less frequently than once a month

$\begin{array}{cc}30 & 29 \\ 78 & 48 \\ 53 & 32 \\ 44 & 6 \\ 16 & 1 \\ 24 & 19\end{array}$

Frequency of visits to the doctor $(p=0.01)$ - Weekly 
Table 3: Association of various factors with the satisfaction of geriatric patients from care provided by their physicians (Continued)

\begin{tabular}{lcc}
\hline - Once every 2-4 weeks & 28 & 12 \\
- Once every 2-3 months & 162 & 77 \\
- Once every 6 months & 44 & 26 \\
- Annually & 4 & 9
\end{tabular}

* Upto grade 5, ** Upto grade 10, *** Upto grade 12, ^ I US \$: 83.23 PK Rupees

Table 4: Multiple logistic regression analysis showing independent predictors of satisfaction of geriatric patients with the care provided

\begin{tabular}{|c|c|c|}
\hline Variables & Adjusted OR* & $95 \% \mathrm{Cl}^{* *}$ \\
\hline \multicolumn{3}{|l|}{ Age in years $(p=0.073)$} \\
\hline$-65-70$ & 1 & - \\
\hline$-71-75$ & 0.89 & $0.49-1.59$ \\
\hline$-76-80$ & 0.69 & $0.39-1.22$ \\
\hline$-81-85$ & 1.16 & $0.6-2.23$ \\
\hline$-86-90$ & 0.24 & $0.07-0.74$ \\
\hline \multicolumn{3}{|c|}{ Cumulative household income in $\mathrm{Pk}$ rupees ${ }^{\wedge}(p=0.005)$} \\
\hline$-<5,000$ & I & - \\
\hline$-5,000-10,000$ & 1.68 & $0.7-4$ \\
\hline$->10,000-25,000$ & 1.14 & $0.54-2.38$ \\
\hline$->25,000-50,000$ & 0.63 & $0.31-1.25$ \\
\hline$->50,000-100,000$ & 0.37 & $0.15-0.88$ \\
\hline$->100,000$ & 0.57 & $0.19-0.72$ \\
\hline \multicolumn{3}{|c|}{ Most important health complaint $(p=0.01)$} \\
\hline - Myalgias/arthralgias & I & - \\
\hline - Dyspnea & 0.93 & $0.25-3.55$ \\
\hline - Nausea/vomiting & 4.16 & $0.84-20.5$ \\
\hline - Insomnia & 3.39 & $1.24-9.3$ \\
\hline -Anorexia & 1.62 & $0.6 \mid-4.3$ \\
\hline - Bed sores & 2.08 & $0.59-7.3$ \\
\hline - Urinary incontinence & 1.98 & $0.95-3.36$ \\
\hline - Urinary retention & 0.5 & $0.17-1.5$ \\
\hline - Fecal incontinence & 1.43 & $0.59-3.44$ \\
\hline \multicolumn{3}{|l|}{ - Constipation } \\
\hline & 2.1 & $0.91-4.86$ \\
\hline \multicolumn{3}{|l|}{ - Memory loss } \\
\hline & 3.5 & $1.58-7.86$ \\
\hline \multicolumn{3}{|c|}{ Frequency of experiencing health complaints $(p<0.00 I)$} \\
\hline - Daily & 1 & - \\
\hline - 2-5 times a week & 1.57 & $0.84-2.93$ \\
\hline - Once a week & 1.60 & $0.81-3.13$ \\
\hline - 2-3 times a month & 7.09 & $2.62-19.15$ \\
\hline - Once a month & 15.47 & $1.92-124.26$ \\
\hline - Less frequently than once a month & 1.22 & $0.55-2.68$ \\
\hline \multicolumn{3}{|c|}{ Frequency of visits to the doctor $(p=0.06)$} \\
\hline & 1 & - \\
\hline - Weekly & 1.42 & $0.45-4.41$ \\
\hline - Once every 2-4 weeks & 3.64 & $1.35-9.78$ \\
\hline - Once every 2-3 months & 2.35 & $0.81-6.81$ \\
\hline - Once every 6 months & 5.23 & $1.05-25.96$ \\
\hline - Annually & & \\
\hline
\end{tabular}

* Odd's ratio, ** Confidence interval, ^ I US \$: 83.23 PK Rupees 
the developed world. We assessed the relationship between the socio-demographic variables and the patient satisfaction with health care. We found that age, most important health complaint and frequency of symptoms experienced had a significant relationship with their level of satisfaction with health care. A previous study from Pakistan has found a statistically significant association between depression in the elderly and satisfaction with health care services [29].

With advancing age, morbidity patterns evolve and transition. The incidence of chronic diseases and psychological ailments increases and rehabilitative support becomes essential [1]. In our study, diabetes and hypertension was present in more than half the patients, and the influence of these co-morbid conditions could be enormous in affecting the overall health and functioning of the geriatric population. A comparison with a Western study assessing the impact of different diseases in geriatric population showed that although the prevalence of hypertension was comparable, diabetes mellitus was a much bigger problem in our region [30].

A better understanding of the processes through which elderly individuals perceive, evaluate, and act on symptoms will enable physicians to respond more appropriately to the needs of older patients. In the same vein, we tried to decipher the expectations of the elderly population by asking specific questions. A significant proportion $(79.2 \%)$ of the participants in our study strongly felt that the physician should discuss all available treatment options thoroughly and involve them in decision making. This is in agreement with previous studies in which the patients expected the physicians to understand the requests that they have regarding how they hope to be helped, and their treatment plan being an agreement between them and their physicians rather than being a unilateral dominion. This bilateral agreement between the physicians and the patients has been termed "concordance" $[8,9]$. This idea is further reinforced in our study in which the participants mentioned that both the patients and their family members should be allowed to talk freely about the illness. The findings in our study also support the notion of the transition of medical practice from a paternalistic model to an autonomous model in developing countries whereby geriatric patients expressed favorable views towards empowerment in the decision making process. In the paternalistic model, the physician makes the decision because it is assumed that he knows what is best for the patient. On the other hand, an autonomous model gives the patients the chance to participate in the decision making process of their care [31].

The participants of our study were keen to be informed about the nature of the disease in clear and simple language. Discussing biomedical issues is more important for the patients than discussing psychological issues. The patients want to hear about the cause and seriousness of their symptoms and about test results in clear and simple language [32]. Hence, it is imperative for the physicians to educate the patients thoroughly regarding the disease. At the same, the patients feel that they should be given a realistic but optimistic picture regarding their health status. This is because unmet expectations adversely affect the doctor-physician relationship. Physician's non-fulfillment of patient's requests plays a significant role in patient's beliefs that physicians did not meet their expectations for care [33].

\section{Strengths and limitations}

This survey provides an insight into the expectations of geriatric patients from their physicians. It was conducted in a developing country with a burgeoning elderly population. As such, this geographical region and this topic are both generally under-represented in medical literature and this document would therefore be an important addition to the armamentarium of medical knowledge. In addition, our questionnaire may be helpful to other investigators who wish to gauge similar parameters in the future.

At the same time, we also acknowledge the following limitations of our study. These limitations must be considered before generalizing the findings of our study to other populations. We aimed to conduct a survey in a selected geriatric patient population at a tertiary care teaching hospital in Karachi, Pakistan. We used convenience sampling to draw this sample. This method of sampling is inherently inferior to probability sampling in its representativeness of the population, and this limits the external validity of the study. Also, this survey was conducted at an ambulatory clinic centre of a high-end hospital of a large cosmopolitan city. As such, individuals of educated, urban backgrounds or belonging to high income bracket would be expected to be encountered there. However, as mentioned before, $\mathrm{CHC}$ is unique in that it receives people from all socioeconomic classes and educational backgrounds and this aspect helped in offsetting this particular limitation of the study. Additionally, interviewers met beforehand to discuss the questionnaire; this measure was intended to reduce the interviewer's bias in the survey. However we acknowledge that the use of interviewing technique for data collection may have introduced some bias in the process although all efforts were made to minimize it.

\section{Conclusion}

We have documented the expectations of the geriatric patients from their physicians in a selected population of geriatric patients encountered at an outpatient centre of a developing country. This is an important step in the improvement of future geriatric-physician interactions. 
Physicians should keep these expectations in mind during their clinical encounters with geriatric patients. Further targeted research on this issue should be carried out in the future to improve the level of care provided to geriatric patients. Specialized geriatric clinics should also be set up utilizing these results.

There is no doubt that geriatrics will rapidly evolve as a medical discipline in the coming years. The goals of geriatric medicine will, however, only be accomplished if geriatricians and their partners work in a system that is designed to provide high-quality and efficient care; a system that recognizes the value and understands the unique nature of the problems of geriatric patients. If the expectations of the patients are adequately met, then the level of satisfaction with health care will surely increase in parallel. Our study is an important step in that direction.

\section{Abbreviations}

CHC: Community Health Center; AKUH: Aga Khan University Hospital; WHO: World Health Organization; SPSS: Statistical Package for Social Sciences

\section{Competing interests}

The authors declare that they have no competing interests.

\section{Authors' contributions}

TS was involved in study conception and design, data collection, entry, analysis, revision, editing and manuscript writing. UK collected and entered data, and participated in writing the manuscript. WQ was involved in study conception, manuscript writing, revision, editing and overall supervision. All authors have read and approved the final manuscript.

\section{Additional material}

\section{Additional file 1}

Questionnaire of Survey. Face-to-face interviews were carried out on the basis of this questionnaire to gauge the expectations of geriatric patients from their physicians.

Click here for file

[http://www.biomedcentral.com/content/supplementary/14726963-9-205-S1.doc]

\section{Acknowledgements}

We would like to acknowledge the help of Mr. Nausherwan Saleem [Year 3 student of Accounting and Finance at Lahore University of Management Sciences (LUMS), Pakistan] for his help with the preparation of the tables and correction of syntax. We are also highly indebted to our reviewers whose comments have helped us improve the quality of the manuscriptimmensely.

\section{References}

I. World Health Organization: Ageing - Exploding the Myths. Geneva. Ageing and Health Programme (AHE); 1999.

2. Department of International Economic and Social Affairs: Periodical on Ageing. Volume I. New York: United Nations; 1985.

3. Population Reference Bureau: The $\mathbf{2 0 0 6}$ World Health Data Sheet, Washington [http://www.prb.org/Publications/Datasheets/ 2006/2006worldpopulationdatasheet.aspx]

4. Zafar SN, Ganatra HA, Tehseen S, Qidwai W: Health and needs assessment of geriatric patients: results of a survey at a teaching hospital in Karachi. J Pak Med Assoc 2006, 56:470-4.

5. Baig LA, Hasan Z, lliyas M: Are the elderly in Pakistan getting their due share in health services? Results from a survey done in the peri-urban communities of Karachi. J Pak Med Assoc 2000, 50:192-6.

6. Taqui AM, Ganatra HA, Zafar SN, Itrat A: Geriatric health in Pakistan: current status and challenges. J Coll Physicians Surg Pak 2008, 18:262.

7. Itrat A, Taqui AM, Qazi F, Qidwai W: Family systems: perceptions of elderly patients and their attendants presenting at a university hospital in Karachi, Pakistan. J Pak Med Assoc 2007, 57:106-10.

8. Eisenthal S, Lazare A: Evaluation of the initial interview in a walk-in clinic. The patient's perspective on a "customer approach". The Journal of Nervous and Mental disease 1976, 162:169-176.

9. Freidin RB, Goldman L, Cecil RR: Patient-physician concordance in problem identification in the primary care setting. Annals of Internal Medicine 1980, 93:490-493.

10. Gravina CF, Garcez-Leme LE, Deckers Leme M, Piegas L: Implantable cardioverter-defibrillators: expectations in the Brazilian elderly. Am J Geriatr Cardiol 2006, I 5:357-60.

1I. Tollén A, Fredriksson C, Kamwendo K: Elderly persons' expectations of day-care rehabilitation. Scand J Occup Ther 2007, 14: $173-82$.

12. Iglesias-Souto PM, Taboada Ares EM, Dosil Maceira A, Cuba López JF: Knowledge and expectations among older adults of social services for the elderly in the Autonomous Region of Galicia (Spain). Rev Esp Geriatr Gerontol 2008, 43:353-61.

13. Rühland $D$ : What treatment expectations does the elderly patient have from surgery and what can surgery achieve? From the viewpoint of vascular surgery. Langenbecks Arch Chir Suppl Kongressbd 1996, I 13:431-3.

14. Körfer R, Kleikamp G: What treatment expectations does the elderly patient have from surgery and what can surgery achieve--from the viewpoint of heart surgery. Langenbecks Arch Chir Suppl Kongressbd 1996, I I 3:434-8.

15. Gepstein R, Arinzon Z, Adunsky A, Folman Y: Decompression surgery for lumbar spinal stenosis in the elderly: preoperative expectations and postoperative satisfaction. Spinal Cord 2006, 44:427-3I.

16. Mills TJ, Smith HC, Vlietstra RE: PTCA in the elderly: results and expectations. Geriatrics 1989, 44:7I-2. 77-9.

17. Lindrooth RC, Hoerger TJ, Norton EC: Expectations among the elderly about nursing home entry. Health Serv Res 2000, 35(5 Pt 2): $1181-202$.

18. von Renteln-Kruse W, Nogaschewski K, Meier-Baumgartner HP: Knowledge concerning illness, expectations and perceptions of treatment of elderly stroke patients and family caregivers-a prospective study during inpatient treatment. Z Gerontol Geriatr 2002, 35:24I-9.

19. Gerstenblith G, Weisfeldt ML: Therapeutic expectations in the middle-aged or elderly hypertensive subject. J Clin Hypertens 1986, 2(3 Suppl):79S-89S.

20. Kutner NG, Brogan D: Expectations and psychological needs of elderly dialysis patients. Int J Aging Hum Dev 1990, 31 : 239-49.

21. Carroll DL: The importance of self-efficacy expectations in elderly patients recovering from coronary artery bypass surgery. Heart Lung 1995, 24:50-9.

22. Groenewald DC, van Vuuren SJ: Perceptions \& expectations of institutionalised elderly people in Bloemfontein. Curationis 1998, $21: 36-45$

23. Takemura $Y$, Kanda K, Matsumoto A, Yamagishi M: Role expectations of nurses in health service facilities for the elderly. Nurs Health Sci 2002, 4:73-83. 
24. World Health Organization definition of Health [http:// www.who.int/about/definition/en/print.html]

25. Bergener M: Geriatrics--a missing discipline? On the need for interdisciplinary care services for psychiatric geriatric patients. Soz Praventiv med 1983, 28:268-73.

26. Channa R, Siddiqi M: What do patients want from their psychiatrist? A cross-sectional questionnaire based exploratory study from Karachi. BMC Psychiatry 2008, 8:14.

27. World Medical Association Declaration of Helsinki [http:// www.wma.net/en/30publications//Opolicies/b3/index.html]

28. Salzman C: Monoamine oxidase inhibitors and atypical antidepressants. Clin Geriatr Med 1992, 8:335-48.

29. Ganatra HA, Zafar SN, Qidwai W, Rozi S: Prevalence and predictors of depression among an elderly population of Pakistan. Aging Ment Health 2008, I 2:349-56.

30. Saks K, Kolk H, Allev R, Soots A, Kõiv K, Paju I, Jaanson K, Schneider $\mathrm{G}$ : Health status of the older population in Estonia. Croat Med J 200I, 42:663-8.

31. Qidwai W: Patient autonomy reflections from a developing country. Am Fam Physician 2005, 71:126I.

32. Tähepold H, Brink-Muinen A van den, Maaroos HI: Patient expectations from consultation with family physician. roat Med J 2006, 47: | 148-54.

33. Bell RA, Kravitz RL, Thom D, Krupat E, Azari R: Unmet expectations for care and the patient-physician relationship. J Gen Intern Med 2002, 17:817-24.

\section{Pre-publication history}

The pre-publication history for this paper can be accessed here:

http://www.biomedcentral.com/1472-6963/9/205/pre

pub

Publish with Biomed Central and every scientist can read your work free of charge

"BioMed Central will be the most significant development for disseminating the results of biomedical research in our lifetime."

Sir Paul Nurse, Cancer Research UK

Your research papers will be:

- available free of charge to the entire biomedical community

- peer reviewed and published immediately upon acceptance

- cited in PubMed and archived on PubMed Central

- yours - you keep the copyright

Submit your manuscript here:

http://www.biomedcentral.com/info/publishing_adv.asp
BiolMedcentral 